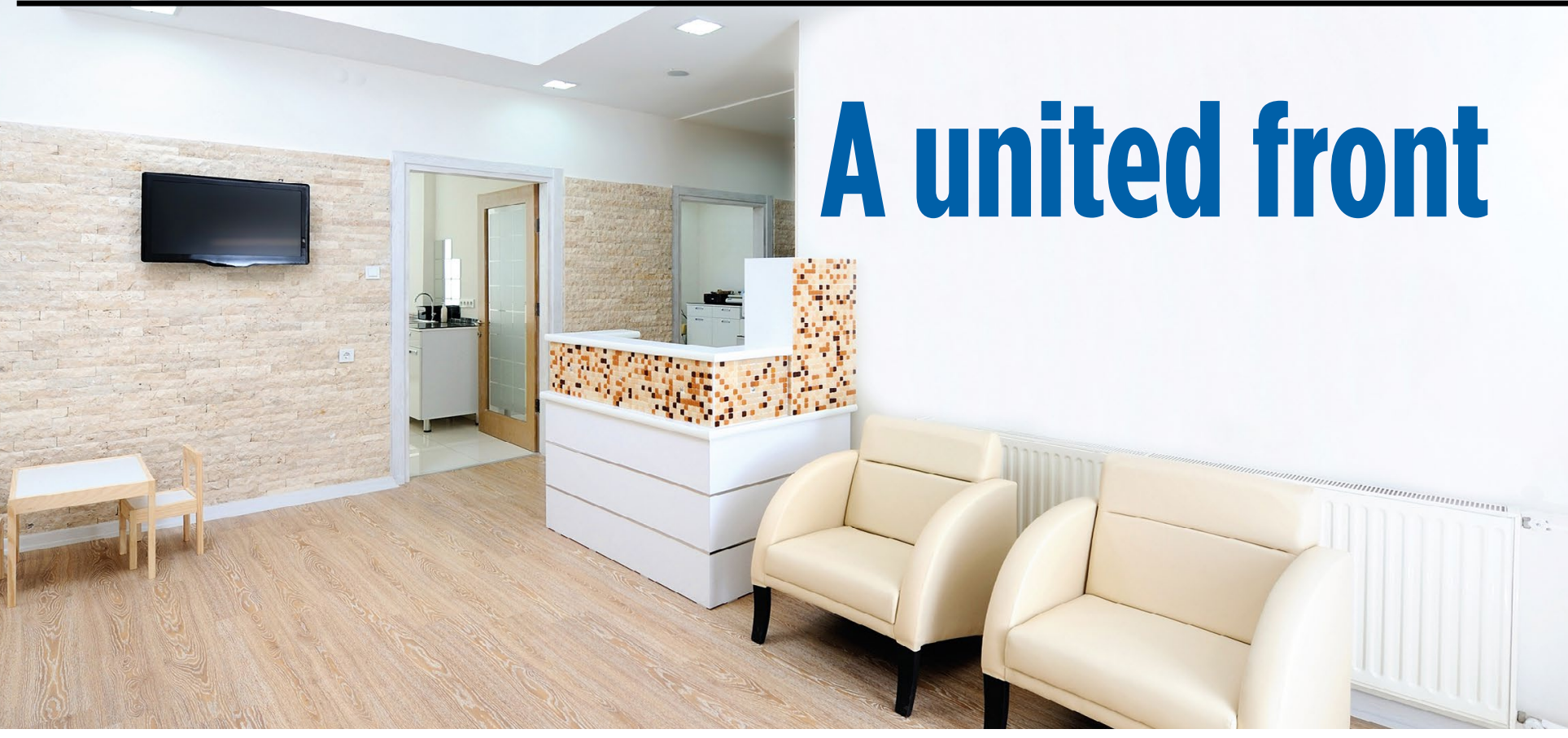

\section{David Westgarth}

Editor, BDJ in Practice

I don't know about you, but I feel a lot like Phil Connors. 'I was in the Virgin Islands once. I met a girl. We ate lobster, drank piña coladas. At sunset we made love like sea otters. That was a pretty good day. Why couldn't I get that day over and over and over?'

Of course, Phil Connors is the character played expertly by Bill Murray in the film Groundhog Day. As another month of seemingly endless lockdown ticks by within the same four walls, it's difficult not to wish for Phil's Virgin Islands experience rather than the current one.

And yet, every now and again, something punctuates the monotony of lockdown, U-turns and depressing spiralling death rates.

In December, social media channels were awash with discussion about the unity of the profession after a press release caused some - largely NHS practitioners - to react with words too unsavoury to print here. A retraction and apology promptly followed, but it got me thinking about the need to remain united throughout these difficult groundhog days.

A recent BDA survey indicated around a third of dental practices were likely to close in the next six months due to the pandemic. Whichever way you cut it, that's a terrifying figure. Imagine that's a private practice with a longstanding patient list, offering access in a part of the country where no NHS dentist is accepting new patients. Imagine that's an NHS practice in an inner-city area with high levels of deprivation and a patient list that struggles to meet NHS dental charges, let alone the cost of living. The ramifications for the patient in each of these scenarios would be incredibly difficult. And, perhaps it's worth remembering when there are heated discussions about 'apparent waste of public monies', that each dental professional is in the job to benefit the patient they're treating.

The reality is for many that feeling of division was sown at the beginning of last March when, in England, the OCDO announced the cessation of dental services with a package of support for NHS contract holders, but nothing for purely private and no clear guidance. From there, you could start to see things snowball, culminating in the aforementioned press release. If you question whether the apparent division exists or not there are plenty who do, and that represents a problem for the longterm harmony of the profession.

Which is why, now more than ever, a united profession is the only way out of the continued darkness cast by COVID19 , lockdown and the dearth of 'routine dentistry'. Even in this third national lockdown dentistry continues, yet plans that took effect on New Year's Day would see NHS practices face steep financial penalties if they fail to hit $45 \%$ of their pre-pandemic NHS activity targets from 1 January to 1 April 2021. How can that be even remotely acceptable to anyone - NHS, mixed or private
- let alone wish to distance themselves from the ensuing furore?

Financial concerns exist for everyone. There isn't one dental professional who has not been affected. Yes, some have fallen through the cracks and been affected more than others - and I have previously written about how Chancellor Rishi Sunak's 'whatever it takes' hasn't applied to this profession in its entirety. Reports of businesses earning too much to qualify for support loans yet not earning enough to survive show just how patchwork government support has truly been. Add to that the current practising environment and you can see why the situation is so precarious. Find me a dental professional who can look me in the eye and tell me fallow time isn't an issue, enhanced PPE isn't an issue, patient flow isn't an issue, finances aren't an issue and the risk of COVID-19 isn't an issue, and I'll show you someone with a troubled relationship with the truth.

While we can only dream of eating lobster and drinking piña coladas, the continued fragmentation of the profession will continue. Until COVID-19 is firmly within our rear-view mirror, we have to stick together. Otherwise, what will the profession look like when that day finally arrives? House Montague and House Capulet, with Romeo and Juliet playing the part of mixed practices? Or will it be a united profession, bettered from the experiences of 2020 and 2021? Only time will tell, but I know which one will be of most benefit to patients.

https://doi.org/10.1038/s41404-021-0649-z 